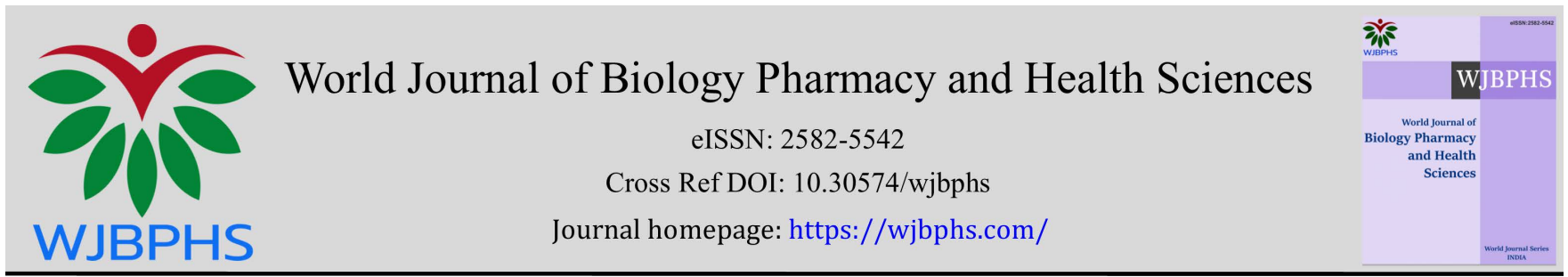

(RESEARCH ARTiCLE)

\title{
Survey study: COVID-19 symptoms and lifestyle
}

\author{
Raida Khalil, Nabaa Khudhair Abdullah*, Dalal Khaldoun Qaddoura and Rahaf Jehad Alash \\ Department of Biotechnology and Genetic Engineering, Faculty of Science, Philadelphia University-Jordan
}

World Journal of Biology Pharmacy and Health Sciences, 2021, 05(02), 033-044

Publication history: Received on 09 January 2021; revised on 10 February 2021; accepted on 12 February 2021

Article DOI: https://doi.org/10.30574/wjbphs.2021.5.2.0015

\begin{abstract}
In the middle of 2020 coronavirus had becoming spread around the world with a high number of people infected with covid-19, which makes covid-19 international pandemic that leads the governments around the world to decided strict roles to prevent the spreading of the virus, like wearing masks, social distance, e-learning and curfew. Because SARSCov2 is a novel virus, research groups around the world are making an effort to study the genetic material and structure of this virus and to find suitable treatment and vaccine. Also, they are trying to analyze the impact on the people who are infected with covid-19 especially after recovering. This preliminary study is trying to analyze the survey data collected from patients in the Middle East especially Jordan and Iraq, to find out how much lifestyle could affect the longlasting symptoms caused by covid-19. According to the data, there is a strong relationship between lifestyle and longlasting symptoms of covid-19 especially physical exercise, taking supplements and drink caffeine frequently.
\end{abstract}

Recommend to get more worldwide study about the impact of lifestyle on the long-lasting symptoms of covid-19.

Keywords: COVID19; Long Lasting Symptoms; Lifestyle

\section{Introduction}

Coronaviruses are relatives of viruses belonging to the Coronaviridae family which are known for holding strains that cause potentially lethal diseases in birds and mammals [1]. In humans, they're generally spread through airborne droplets of liquefied produced by infected persons. When initially described intimately within the 1963s by June Almeida [2], the coronavirus gets its name from a particular corona or 'crown' of sugary-proteins that present on their envelope surface [3].

Until 2002, coronaviruses were first recognized to cause cold in humans [4]. although some rare strains, including SARSCoV-2 (that cause COVID-19), and people liable for severe acute respiratory syndrome (SARS) and the Middle East respiratory syndrome (MERS), are able to cause death in humans [4].

SARS-Cov was first recognized as a distinct strain of coronavirus in 2003 [5]. The origin of the virus has never been known yet, though the primary human infections are often traced back to the Chinese province of Guangdong in 2002. The virus at that time became pandemic, causing relatively 8,000 infections of an influenza-like disease in 26 countries with nearly 800 deaths, according to World Health Organization (WHO) data explorer.

Then in 2013, the MERS-Cov was first recognized in Saudi Arabia in patients displaying symptoms of fever, cough, shortness of breath, and sometimes gastrointestinal problems like diarrhea [6]. An animal cause for the virus has never been officially confirmed, however, evidence points to dromedary camels as a possible reservoir of infection. The World

\footnotetext{
${ }^{*}$ Corresponding author: Nabaa Khudhair Abdullah

Philadelphia University- Jordan.

Copyright (C) 2021 Author(s) retain the copyright of this article. This article is published under the terms of the Creative Commons Attribution Liscense 4.0.
} 
Health Organization (WHO) has identified about 2,500 cases of infection in 27 countries since the initial outbreaks, and nearly 860 people died.

In December 2019, a new Coronavirus strain was identified in Wuhan, China [7]. First, it was called 2019-nCov and then SARS-CoV-2 for severe acute respiratory syndrome Coronavirus 2 [8]. SARS-CoV-2 spreads very efficiently, causing the current COVID-19 (Coronavirus Disease 2019) pandemic, which by the end of December 2020 has already infected more than 81 million people and killed more than 1.7 million people all over the world according to World Health Organization COVID-19 EXPLORER website. Actually at the time of writing, the number of infected people is still increasing.

Snakes were originally assumed as a possible source for the outbreak, though other experts have deemed these unlikely and proposed bats as a reservoir instead [9]. Pangolins are implicated as a possible link within the transfer chain.

People who suffer from covid-19 show different symptoms but according to WHO, most of them share these common symptoms like fever, dry cough, and tiredness. People who suffer from infection in the respiratory system range from mild to severe. Mild patients show symptoms like aches, pain, sore throat, loss of taste or smell, rash on skin or discoloration of fingers or toes, conjunctivitis, and slight shortness of breath. Severe symptoms are difficulty breathing or shortness of breath, chest pain or pressure, loss of speech or movement. While people who suffer from infection in the gastrointestinal tract show diarrhea, nausea, anorexia, vomiting, and strong pain in the stomach. Around $20 \%$ of the total cases don't show any symptoms. Coronaviruses built on phylogenetic relationship and genomic structure reveals that SARS-COV-2 is a part of beta Coronaviruses [10]. Human beta Coronaviruses (SARS-COV-2, SARS-COV) have many similarities but have changes in their genomic and phenotype structure that can impact their pathogenesis.

SARS-COV-2 is a sphere shape or pleomorphic enveloped particles having single-strand RNA related with a nucleoprotein within capsid comprised of matrix protein [11], SARS-COV-2 genome containing (26.4- 31,7 kbp) with GC content variable from $32 \%$ to $43 \%$ and contain 4 major structure proteins spike (S), envelop (E) , membrane (M) and nucleocapsid (N).

The viral genome consists of distinctive structures, as long as a unique $\mathrm{N}$-terminal fragment within the spike protein, genes for the main structural proteins in all coronaviruses occur in the $5^{\prime}-3^{\prime}$ order as $S, E, M$, and $N$ [12]; Proteins are encoded by open reading frame (ORFs) [13]. The most plentiful structural protein is the membrane (M) glycoprotein. The spike (S) protein is a major inducer of neutralizing antibodies. Among the four major structural proteins, the $\mathrm{E}$ protein is the smallest one and participates in viral assembly and budding [11,12].

The first steps of coronavirus infection contain the specific binding of the coronavirus spike (S) protein to the cellular entry receptors, which have been recognized for some coronaviruses. The expression and tissue spreading of entry receptors affect viral tropism and pathogenicity through the intracellular life cycle.

Coronaviruses express and replicate their genomic RNA to create full-length copies that are fused into newly created viral particles, they have bulky RNA genomes bordered by $5^{\prime}$ and $3^{\prime}$ untranslated areas that include cis-performing secondary RNA structures necessary for RNA synthesis. The positive-sense single-stranded RNA genome (+SsRNA) is encapsulated by $\mathrm{N}$, while $\mathrm{M}$ and $\mathrm{E}$ make sure its combination in the viral particle during the assembly process , $\mathrm{S}$ trimmers stand out from the host-derived viral envelope and supply specificity for cellular entrance receptors.

Coronavirus particles bind to cellular correlation factors and specific S interactions with the cellular receptors (as angiotensin-converting enzyme 2 (ACE2)), together with host factors (as the cell surface serine protease TMPRSS2), stimulate viral uptake and incorporation at the cellular or endosomal membrane [14-17]. Next entrance, the release and un-coating of the incoming genomic RNA subject it to the direct translation of two large open reading frames, ORF1a and ORF1b. The resultant polyproteins pp1a and pp1ab are co-translationally and post-translationally treated into the individual non-structural proteins (NSPS) that take shape the viral replication and transcription complex, concurrent with the expression of NSPS, the biogenesis of viral replication organelles consisting of characteristic perinuclear double-membrane vesicles (DMVs), convoluted membranes (CMs) and small open double-membrane spherules (DMSs) make a protective microenvironment for viral genomic RNA replication and transcription of sub-genomic mRNAs (sg mRNAs) including the characteristic nested set of coronavirus mRNAs.

Translated structural proteins translocate into endoplasmic reticulum (ER) membranes and transit over the ER-to-Golgi intermediate compartment (ERGIC), wherever interaction with $\mathrm{N}$-encapsulated, newly produced genomic RNA results in budding into the lumen of secretary vesicular compartments. 
Lastly, virions are secreted from the infected cell through exocytosis [18].

Since covid-19 is a novel disease, most of the long-lasting symptoms; symptoms post covid infection, are still not clear yet. This preliminary study is about long-lasting covid symptoms that may reveal some information about these symptoms and their correlation with lifestyle.

\section{Aim}

This survey aims to predict out what are the symptoms that come after having covid-19 (long-lasting symptoms) and the correlation between lifestyle (habit), age, gender by analyzing Google document questionnaires in table (1). The data was collected from $4^{\text {th }}$ of November 2020 to the $11^{\text {th }}$ of December 2020.

\section{Material and methods}

\subsection{Scanning methodology}

The current survey is done by under graduated students from the department of biotechnology and genetic engineering at Philadelphia university-Jordan. Web-scanning was conducted to collect the data from The Hashemite Kingdom of Jordan, Iraq, and neighboring countries about participant's symptoms during and after infection by coronavirus during the Covid-19 Pandemic.

The data was collected from the $4^{\text {th }}$ of November to $11^{\text {th }}$ of December 2020 using Google document that can be shared with anyone by using the Internet network using social media applications (Facebook, Twitter, Instagram and what's up). On the other hand, the method of administration provides statistical information. It's not controlled but it was useful to the current survey, because it makes collecting information from participants easier and more safety, since that the Jordanian government decided to use e-learning in schools and universities and curfew.

These data depend on the internet users in this area and the people who responded to this questionnaire.

\subsection{The designed covid-19 questionnaire}

The utilize-covid-19 questionnaire in this current survey was done by using Google document form. The questionnaire consists of 15 questions include:

- Personal data, like the previous history of the disease, age, gender, location (where they live).

- Lifestyle/habit (smoking, sleeping, physical exercise, using food supplements or not).

- $\quad$ Symptoms and long-lasting symptoms.

Table 1 Appendix: Questionnaire

\begin{tabular}{|c|c|}
\hline Question & Answers \\
\hline Age & $\begin{array}{l}<18 \\
18-25 \\
25-35 \\
35-50 \\
>50\end{array}$ \\
\hline $\begin{array}{l}\text { Gender } \\
\text { Location }\end{array}$ & $\begin{array}{l}\text { Male/Female } \\
\text { (depend) }\end{array}$ \\
\hline Are you still infected with Coronavirus? & Yes/No \\
\hline Do you have any symptoms? & Yes/No \\
\hline Did you do a Corona test? & Yes/No \\
\hline How long did the infection last? & Week/Tow weeks/More than two weeks \\
\hline
\end{tabular}




\begin{tabular}{|l|l|}
\hline Symptoms you suffered : & $\begin{array}{l}\text { Fever/Dry cough/Headache/Sore } \\
\text { throat/Shortness of breath /Loss of Smell } \\
\text { sense and taste/Fatigue/Nausea/Pain in } \\
\text { the stomach/Rash/Diarrhea/Joint pain } \\
\text { Others ... }\end{array}$ \\
\hline $\begin{array}{l}\text { Have you taken nutritional supplements ( e.g. vitamins } \\
\text { or minerals)? }\end{array}$ & $\begin{array}{l}\text { Take before infection/Take after } \\
\text { infection/never }\end{array}$ \\
\hline $\begin{array}{l}\text { Do you suffer from chronic Disease?( if you have } \\
\text { mention it) }\end{array}$ & Yes/No \\
\hline Do you practice any of these behaviours? & $\begin{array}{l}\text { Practice sport } \\
\text { Get enough sleep } \\
\text { Drink a lot of stimulants (like coffee) } \\
\text { Have a healthy food } \\
\text { Smoke } \\
\text { Others... }\end{array}$ \\
\hline $\begin{array}{l}\text { Are you still suffering from } \\
\text { some side effects after your recovery? } \\
\text { Mention these symptoms? }\end{array}$ & Yes/No \\
Did you get infected again? & (depend) \\
Mention the period between the two infectious? & Yes/No \\
\hline Total & (depend) \\
\hline
\end{tabular}

\section{Results}

The Google document web-survey duration was from the $4^{\text {th }}$ of November 2020 to the $11^{\text {th }}$ of December 2020, and the collected data was analyzed. The total numbers of participants were 413 , only 402 who had completed the questionnaire were involved in the study and the age range was extended below 18 to over 50 years old.

Table 2 General information about age, gender and chronic disease with location

\begin{tabular}{|c|c|c|c|}
\hline \multicolumn{1}{c}{ Parameter/location } & Jordan (33.8\%) & Iraq (48.3\%) & Neighbour countries (17.9\%) \\
\hline Age group (year) & & & \\
$<18(9.2 \%)$ & $5(13.6 \%)$ & $16(43.2 \%)$ & $16(43.2)$ \\
$18-25(45.8 \%)$ & $48(26 \%)$ & $114(62 \%)$ & $22(12 \%)$ \\
$25-35(19.4 \%)$ & $41(53.2 \%)$ & $28(36.4 \%)$ & $8(10.4 \%)$ \\
$35-50(18.7 \%)$ & $32(42.7)$ & $21(28 \%)$ & $22(29.3 \%)$ \\
$>50(7 \%)$ & $10(34.5 \%)$ & $15(51.7 \%)$ & $4(13.8 \%)$ \\
\hline Gender: & & & $47(16.2)$ \\
female (72.1\%) & $98(33.8 \%)$ & $145(50 \%)$ & $25(22.3 \%)$ \\
male (27.9\%) & $38(33.9 \%)$ & $49(43.8 \%)$ & $6(8.8 \%)$ \\
Chronic disease & $24(35.3 \%)$ & $38(55.9 \%)$ & $\mathbf{7 2}$ \\
\hline
\end{tabular}


As shown in table 2, responses from Iraq were $48.3 \%$ of the participants which females did responded more than males; approximately $72.1 \%$ of the participants were females and $27.2 \%$ males. Most of participants aged between 18 to 25 , $26 \%$ of them live in Jordan, $62 \%$ in Iraq and $12 \%$ from other neighboring countries. Less of them were above 50 years, $34.5 \%$ live in Jordan, $51.7 \%$ in Iraq and $13.8 \%$ live in other neighboring countries. According to gender data analysis, $72.1 \%$ of data were females and $27.9 \%$ males. $33.8 \%$ of females live in Jordan, $50 \%$ in Iraq and $16.2 \%$ in other neighboring countries. While $33.9 \%$ of males live in Jordan, $43.8 \%$ in Iraq and $22.3 \%$ in other neighboring countries. However, only $16.9 \%$ of participants have a chronic disease, which $35.3 \%$ of them live in Jordan, $55.9 \%$ in Iraq and $8.8 \%$ other neighboring countries.

Since there was a significant difference between the numbers of participants; females compared to males, we cannot get clear data about the correlation between the appearances of the symptoms, whether during infection or long-lasting symptoms. The gender parameter cannot be used in this study to find out their correlation with symptoms appearance (Figure 1).

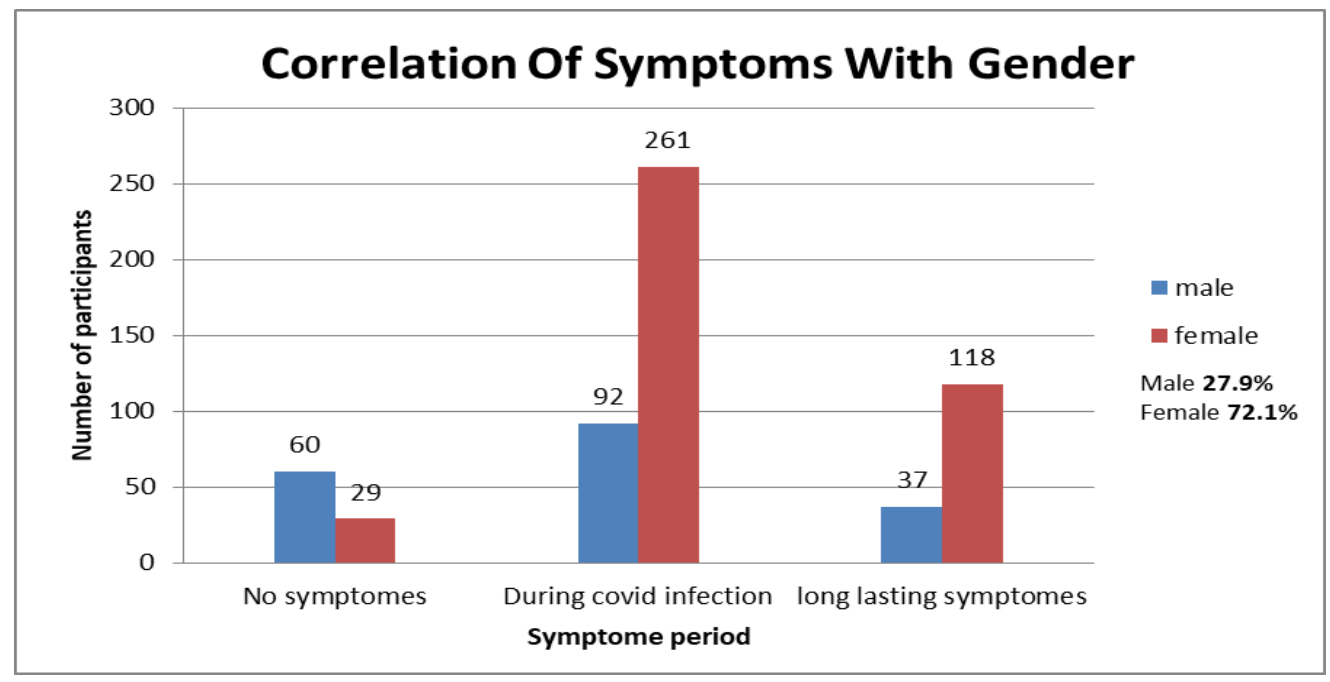

Figure 1 Correlation of symptoms with gender

Concerning the participants lifestyle who infected with COVID-19, 138(34.3\%) participants declared to do physical exercises, $91(22.6 \%)$ early sleeping, regarding to the drink water frequently the highest percentage of the respondents declared 202(50.2\%), 103(25.6\%) drink a lot of stimulants and 139(34.6\%) were taking supplements. Furthermore, $139(34.6 \%)$ of the respondents affirmed to smoking (Table 3$)$.

Table 3 General information about lifestyle (smoking, sleeping, physical exercise, etc.) pre COVID-19 infection

\begin{tabular}{|c|c|}
\hline Lifestyle & Pre Covid19 infection \\
\hline Physical exercises & $138(34.3 \%)$ \\
\hline Sleep enough & $91(22.6 \%)$ \\
\hline Drink water frequently & $202(50.2 \%)$ \\
\hline Drink caffeine frequently & $103(25.6 \%)$ \\
\hline Supplements ( vitamins and trace elements) & $139(34.6 \%)$ \\
\hline Smoking & $82(20.4 \%)$ \\
\hline Total & 402 \\
\hline
\end{tabular}

Table 4, shows the results of the survey about covid-19 symptoms during infection and long-lasting symptoms after recovery. Regarding to this table, $12.2 \%$ of the participants have no symptoms while $87.8 \%$ show symptoms during the infection stage, $57.9 \%$ show no symptoms and $44.5 \%$ show long-lasting symptoms after the recovery stage. The first column shows 30 different symptoms that the participants may have during infection or after recovery, while the 
second column displays each symptom during infection and how many participants suffer from it with the percentage. The third column presents participants who are ailing from long-lasting symptoms.

Table 4 General information about symptoms during Covid-19 infection and long-lasting symptoms after recovery

\begin{tabular}{|c|c|c|}
\hline Criteria & Symptoms During infection & Long lasting Symptoms \\
\hline No symptom & $49(12.2 \%)$ & $223(55.4 \%)$ \\
\hline With symptom & $353(87.8 \%)$ & $179(44.5 \%)$ \\
\hline Fever & $252(62.6 \%)$ & $3(0.7 \%)$ \\
\hline Cough & $194(48.3 \%)$ & $15(3.7 \%)$ \\
\hline Headache & $284(70.6 \%)$ & $17(4.22 \%)$ \\
\hline Pneumonia & $2(0.5 \%)$ & 0 \\
\hline Sore throat & $158(39.3 \%)$ & $(\% 1.4) 6$ \\
\hline Shortness of breath & $163(40.5 \%)$ & $17(4.22 \%)$ \\
\hline Tiredness & $317(78.9 \%)$ & $25(6.2 \%)$ \\
\hline Nausea & $147(36.6 \%)$ & $4(0.9 \%)$ \\
\hline Stomach-ache & $113(28.3 \%)$ & $2(0.4 \%)$ \\
\hline Rash & $26(6.5 \%)$ & $2(0.4 \%)$ \\
\hline Diarrhea & $140(34.8 \%)$ & $6(1.4 \%)$ \\
\hline Joint pain & $189(46 \%)$ & $15(3.7 \%)$ \\
\hline Loss of smell or tasting & $276(68.7 \%)$ & $51(12.6 \%)$ \\
\hline Redness in eyes & $2(0.5 \%)$ & 0 \\
\hline dizziness & $2(0.5 \%)$ & $1(0.2 \%)$ \\
\hline Running cold & $3(0.7 \%)$ & 0 \\
\hline Blood clot & $1(0.2 \%)$ & 0 \\
\hline Decrease in blood pressure & $1(0.2 \%)$ & $1(0.2 \%)$ \\
\hline Dry nose & $3(0.7 \%)$ & 0 \\
\hline Loss of appetite & $1(0.2 \%)$ & $1(0.2 \%)$ \\
\hline Hair lose & 0 & $5(1.2 \%)$ \\
\hline Thoracic cavity and lung pain & 0 & $6(1.4 \%)$ \\
\hline Allergy and sinuses problem & 0 & $3(0.7)$ \\
\hline Problem in skin like roughness & 0 & $1(0.2 \%)$ \\
\hline high heart beats & 0 & $1(0.2 \%)$ \\
\hline Chest or lung pain & 0 & $10(2.4 \%)$ \\
\hline Bad smell or taste in food & 0 & $4(0.9 \%)$ \\
\hline Heart muscle pain & 0 & $1(0.2 \%)$ \\
\hline Asthma become more worse & 0 & $1(0.2 \%)$ \\
\hline Back pain & 0 & $2(0.4 \%)$ \\
\hline Total & 402 & 402 \\
\hline
\end{tabular}

We noticed that the most covid-19 symptoms showed by participants are tiredness (78.9\%), headache (70.6\%), loss of smell and taste $(68.7 \%)$, fever (62.6\%), and cough (48.3\%). The moderate symptoms were cough (48.3\%), joint pain (46\%), shortness of breath (40.5\%), sore throat (39.3\%), nausea (36.6\%), diarrhea (34.8\%), stomachache (34.8\%), and rash $(26.5 \%)$. While less common symptoms were running cold $(0.7 \%)$, dry nose $(0.7 \%)$, and redness in eyes $(0.5 \%)$. The percentage above is logical and compatible with the symptoms approved by the World Health Organization (WHO). As the third column shows in this survey, we can tell that the most long lasting symptoms common were loss smell or taste $(12.6 \%)$, tiredness (6.2\%), headache (4.22\%), shortness of breath $(4.22 \%)$, cough (3.7\%), and joint pain (3.7\%). On the other hand, the less common were dizziness $(0.5 \%)$, decrease of blood pressure $(0.2 \%)$, problem in skin $(0.2 \%)$, 
high heartbeats $(0.2 \%)$, heart muscle pain $(0.2 \%)$, and asthma patient suffer from worse asthma crisis than usual $(0.2 \%)$. And these low percentage symptoms added due to our experience with the participants, also according to the present knowledge we note that there is new lasting symptoms that until now other research not mention it yet. It was smell everything bad even perfume and bad taste in various type of food that make you can't even eat the meal (Table 4).

As shown in table 5, the most common symptoms during infection in age group $<18$ were headache and fever while the least common was diarrhea. But the most common symptoms in age group 18-25 were tiredness and fever, though the least common was stomachache. In age group above 50 we can see that the most common symptom were tiredness and loss of smell/tasting, however, the least common was stomachache.

Table 5 Correlation of symptoms during infection with age.

\begin{tabular}{|l|l|l|l|l|l|}
\hline \multicolumn{1}{l}{ Criteria } & \multicolumn{1}{l}{ Age $<\mathbf{1 8}$} & \multicolumn{1}{l}{ Age 18-25 } & \multicolumn{1}{l}{ Age 25-35 } & \multicolumn{1}{l}{ Age 35-50 } & \multicolumn{1}{c}{ Age >50 } \\
\hline Fever & $25(78.1 \%)$ & $123(75.9 \%)$ & $32(50.8 \%)$ & $44(62.9 \%)$ & $19(73.1 \%)$ \\
Cough & $20(62.5 \%)$ & $90(55.6 \%)$ & $33(52.3 \%)$ & $32(45.7 \%)$ & $15(57.7 \%)$ \\
Tiredness & $23(71.9 \%)$ & $136(83.9 \%)$ & $56(88.9 \%)$ & $55(78.6 \%)$ & $23(88.7 \%)$ \\
\hline Headache & $29(90.6 \%)$ & $128(79 \%)$ & $46(73 \%)$ & $43(61.4 \%)$ & $16(61.5 \%)$ \\
Diarrhea & $6(18.8 \%)$ & $68(41.9 \%)$ & $27(42.9 \%)$ & $16(22.9 \%)$ & $11(42.3 \%)$ \\
Stomach-ache & $8(25 \%)$ & $49(30.2 \%)$ & $21(33.3 \%)$ & $23(32.9 \%)$ & $5(192 \%)$ \\
Nausea & $9(28.1 \%)$ & $77(47.3 \%)$ & $16(25.4 \%)$ & $24(34.3 \%)$ & $9(34.6 \%)$ \\
Joint pain & $19(59.3 \%)$ & $6540.1 \%)$ & $37(58.7 \%)$ & $43(61.4 \%)$ & $13(50 \%)$ \\
Sore throat & $12(37.5 \%)$ & $61(37.7 \%)$ & $26(41.3 \%)$ & $32(45.7 \%)$ & $14(53.8 \%)$ \\
Shortness of breath & $16(50 \%)$ & $79(48.8 \%)$ & $33(52.4 \%)$ & $29(41.4 \%)$ & $12(46.2 \%)$ \\
Loss of smell/tasting & $26(81.3 \%)$ & $109(67.3 \%)$ & $47(74.6 \%)$ & $53(75.7 \%)$ & $23(88.5 \%)$ \\
\hline
\end{tabular}

Source: collected from the filled-in questionnaire; Google document form.

We can only compare between groups aged 25-35 and 35-50, since the number of participants are close to each other. In those two groups, the most common symptoms were tiredness and loss of smell/taste. While they differ in the least common symptom, the least common symptom in the age group 25-35 was nausea, and in the age group 35-50 was diarrhea (figure 2).

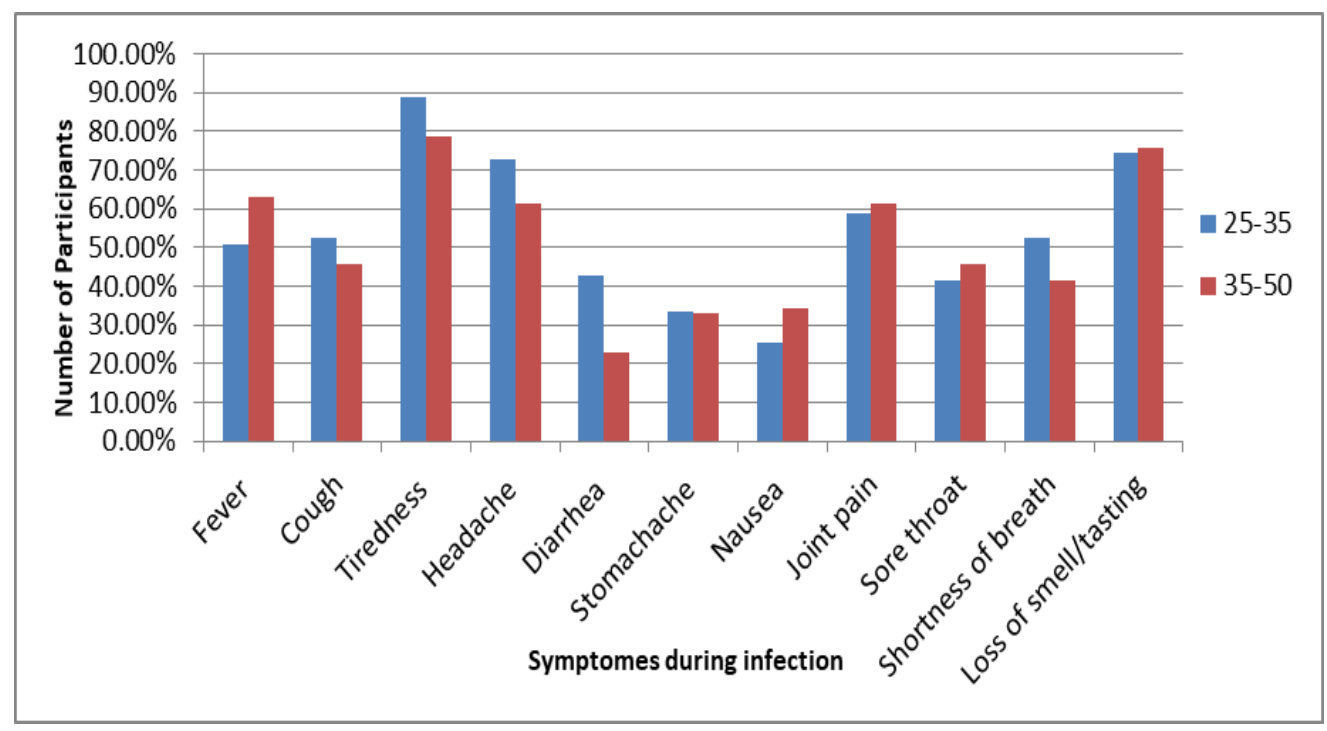

Figure 2 Correlation Of Symptoms During Infection With Age Groups 25-35 And 35-50. 
Refer to the data in table 6 , in the age group $<18$ generally most of participants did not show long lasting symptoms, however the most common long lasting symptoms were loss of smell/taste and the least were headache and joint pain, while no one of participants showed cough and shortness of breath. In the age group 18-25 the most long-lasting symptoms were loss of smell/tasting and the least common was cough. Participants in age group above 50 did not show cough and the common symptom was tiredness while the least were shortness of breath, headache, tiredness, joint pain and loss of smell/tasting.

Table 6 Correlation of Long Lasting Symptoms with Age Groups.

\begin{tabular}{|l|l|l|l|l|l|l|}
\hline Criteria & Age $<$ 18 & Age 18-25 & Age 25-35 & Age 35-50 & Age $>$ 50 \\
\hline Cough & 0 & 8 & 2 & 5 & 0 \\
\hline tiredness & 2 & 13 & 6 & 5 & 2 \\
\hline Shortness of breath & 0 & 9 & 1 & 4 & 1 \\
\hline Headache & 1 & 13 & 3 & 5 & 1 \\
\hline Joint pain & 1 & 9 & 6 & 3 & 1 \\
\hline Loss of smell/tasting & 3 & 28 & 8 & 14 & 1 \\
\hline Total & $\mathbf{8}$ & $\mathbf{7 3}$ & $\mathbf{3 2}$ & $\mathbf{3 5}$ & $\mathbf{7}$ \\
\hline
\end{tabular}

Source: collected from the filled-in questionnaire; Google document form.

Comparing to each others, the participants in age groups 25-35 and 35-50 showed the same common long-lasting symptom which was the loss of smell/tasting. Though they differed in the least common symptoms, which were shortness of breathe, and joint pain in the age group 25-35 and 35-50 respectively (Figure 3).

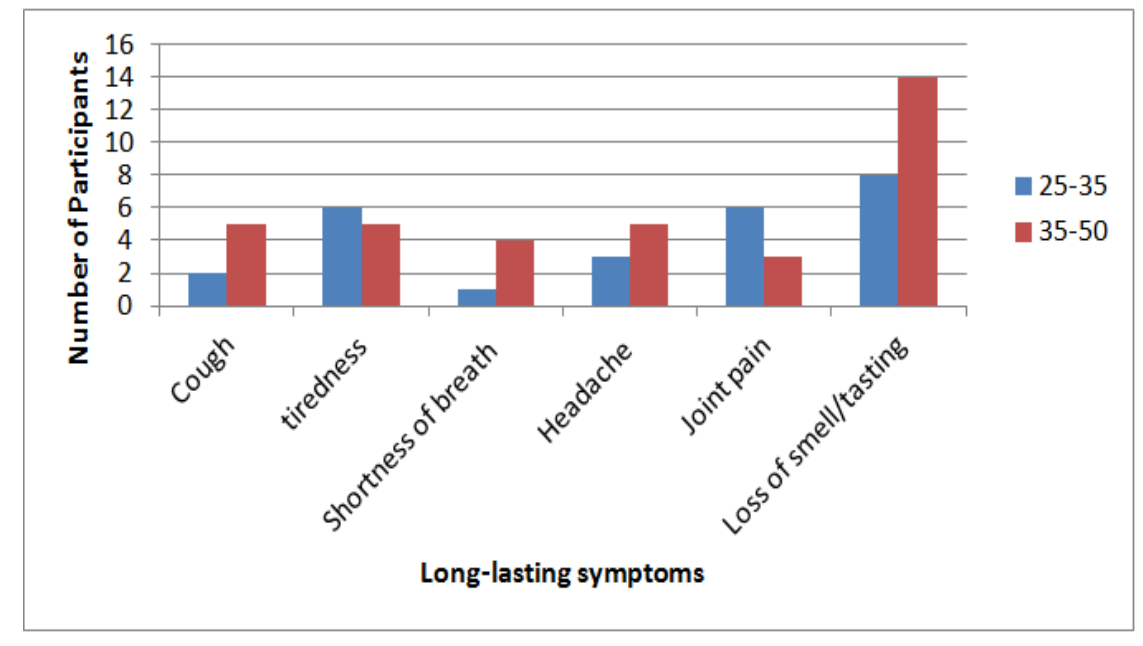

Figure 3 Correlation Of Long-Lasting Symptoms With Age Groups 25-35 And 35-50.

Among the total number of participants of this study which was 402, only 155 of them showed long-lasting symptoms. Refer to data in table 7, about 34.8\% , 53.5\%, 41.3\%, 27.1\%, 20\%, 59.4\% of the participants with long-lasting symptoms were doing physical exercises, drink water frequently, take supplements, drinks caffeine frequently, smoking and sleep enough, respectively. Also 247 of participants did not show any long-lasting symptoms, the majority of them were drinking water frequently (48.2\% participants), and 57.2\%,34\%,30\%, 25.1\%, 18.6\% , have enough sleep, doing physical exercises, take supplements, drink a lot of caffeine, and smoking, respectively (Table 7, figure 4). 
Table 7 Correlation of long-lasting symptoms with lifestyle

\begin{tabular}{|c|c|c|c|c|c|c|}
\hline Criteria & $\begin{array}{l}\text { Physical } \\
\text { exercises }\end{array}$ & $\begin{array}{l}\text { Drink } \\
\text { water } \\
\text { frequently }\end{array}$ & $\begin{array}{l}\text { *Take } \\
\text { supplements }\end{array}$ & $\begin{array}{l}\text { Drink } \\
\text { caffeine } \\
\text { frequently }\end{array}$ & Smoking & Sleep well \\
\hline Cough & $2(3.7 \%)$ & $5(6 \%)$ & $6(9.4 \%)$ & $9(21.4 \%)$ & $2(6.5 \%)$ & $6(6.5 \%)$ \\
\hline tiredness & $9(16.7 \%)$ & $12(14.5 \%)$ & $6(9.4 \%)$ & $9(21.4 \%)$ & $4(12.9 \%)$ & $17(18.5 \%)$ \\
\hline Shortness of breath & $6(11.1 \%)$ & $11(13.3 \%)$ & $2(3.1 \%)$ & $3(7.1 \%)$ & $2(6.5 \%)$ & $9(9.8 \%)$ \\
\hline Headache & $11(20.4 \%)$ & $15(18.1 \%)$ & $6(9.4 \%)$ & $3(7.1 \%)$ & $4(12.9 \%)$ & $9(9.8 \%)$ \\
\hline Joint pain & $5(9.3 \%)$ & $8(9.6 \%)$ & $4(6.3 \%)$ & $2(4.8 \%)$ & $1(3.2 \%)$ & $8(8.7 \%)$ \\
\hline Loss of smell/tasting & $21(38.9 \%)$ & $27(32.5 \%)$ & $14(21.9 \%)$ & $14(33.3 \%)$ & $11(35.5 \%)$ & $33(35.9 \%)$ \\
\hline No lasting symptoms & $84(34 \%)$ & $119(48.2 \%)$ & $74(30 \%)$ & $62(25.1 \%)$ & $46(18.6 \%)$ & $142(57.5 \%)$ \\
\hline Total & 138 & 202 & 138 & 104 & 77 & 234 \\
\hline
\end{tabular}

*supplements like vitamins and trace elements.

Source: collected from the filled-in questionnaire; Google document form.

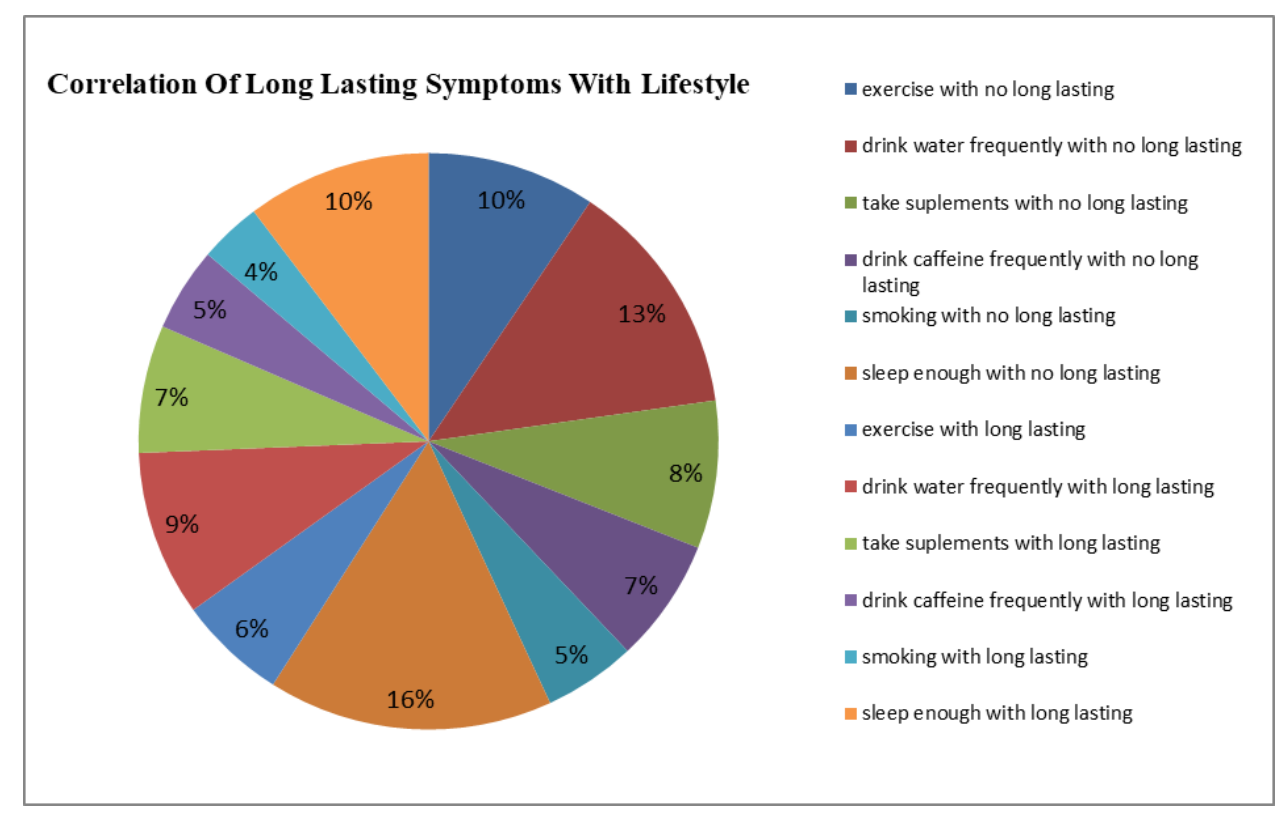

Figure 4 Correlation Of Long-Lasting Symptoms With Lifestyle.

\section{Discussion}

After the analysis of survey data, we figured out that there was a strong relationship between lifestyle and long-lasting symptoms of covid-19.

The previous study was indicated that there is a correlation between physical exercise and immune systems. Physical exercise enhances the immune system through the activation of neutrophils, macrophages, and natural killer cells (NK) [19]. Also, it reduces sensibility to infections, mainly respiratory infections together with COVID-19 [19]. Additionally, this study suggested that the presence of caffeine as a part of lifestyle could optimize the metabolic and immunoprotective profits, especially when combined with exercise [19].

Following the role of the immune system and physical exercise, our result from the present study predicts that $34 \%$ of participants who not suffering long-lasting symptoms of covid-19 considered physical exercise as a part of their lifestyle. Though $65 \%$ of participants who display long-lasting symptoms were not considered exercise as a part of their lifestyle. On the other hand, the current study may agree with the effectiveness of the caffeine in that $73 \%$ of participants with no long-lasting symptoms were drinking caffeine frequently. 
Otherwise, vitamins and trace elements play important role in protecting against respiratory viral infections include COVID-19 by enhancing the immune system. Related to another study that says, vitamin $\mathrm{C}$ decreases inflammation by enhancing the immune system against viral infections [20]. In the study case, there was 74-year-old female infected with COVID-19 showed acute respiratory distress syndrome and septic shock. The female was treated with high-dose intravenous vitamin C (11 g/d for $10 \mathrm{~d})$ and showed rapid recovery. Vitamin D plays important role in the production of an antimicrobial peptide in epithelium cells of the lung which is might prevent the invasion of the coronavirus, and modify T helper cell response. A meta-analysis on 1369 patients infected with the covid-19 show that the death rate of hospitalized COVID-19 patients who had enough vitamin D level (serum 25-hydroxy vitamin D $\geq 30 \mathrm{ng} / \mathrm{mL}$ ) was $5 \%$; however, patients who have severe vitamin D deficiency (serum 25 -hydroxy vitamin D $<10 \mathrm{ng} / \mathrm{mL}$ ) had a $50 \%$ death rate after $10 \mathrm{~d}$ of hospitalization. Trace elements, especially selenium, work as antiviral by their effect on the regulation of CD4+ T cell receptors, and antibody production [20]

In the current study there were $29 \%$ of participants with no long-lasting symptoms, consider vitamins and trace elements as part of their lifestyle.

We should note that many factors affect the severity of long-lasting symptoms.

Our preliminary study provides new insight into the relationship between sleep enough and long-lasting symptoms of covid-19. The survey data display that $41.6 \%$ of participants who do not show long-lasting symptoms were sleeping enough. Also, drink water frequently may help to avoid long-lasting symptoms, since data reveal that $48.2 \%$ of participants who were drinking water frequently show no long-lasting symptoms. Though there is no previous study showed in the literature review considering the relationship between drink water frequently, sleep, and long-lasting symptoms of covid-19.

Since it was a survey preliminary study, the data were not able to control.

Data in this study observed that participants in the age group 18-25 showed most symptoms related to their age, which may indicate that there is a variation in the SARS-2 of the Middle East, but there are no previous studies related to this issue.

Lifestyle can affect long-lasting symptoms more than we thought. This preliminary study gives important data about how much lifestyle like physical exercise, take supplements and drink caffeine frequently may affect on long lasting symptoms. These could help people to avoid dangerous complications which are caused by long lasting symptoms of covid. Depending on the survey data we were unable to do statistical correlation due to age factor and gender. The sample size was also small, which is considered a drawback.

Recommended getting more world-wild studies in collaboration with a research group to get a more clear picture about this kind of study which will allow finding out the age factor and lifestyle with long-lasting symptoms of covid-19. Further research may need to establish the relationship of covid-19 with the regulation of interleukins and blood groups in addition to lifestyle in generally speaking.

\section{Conclusion}

Covid-19 is international pandemic affects millions of people around the world and it is important to study the impact of this virus during and after infection. According to our preliminary study about covid-19 Long-lasting symptoms and Lifestyle, we figured out that taking supplements, physical exercise and drink caffeine frequently may affect the longlasting symptoms while sleeping enough, drinking water and smoking do not affect Long-Lasting symptoms. Also the result shows that there is no relationship between lifestyle and loss of smell and tasting.

Hoping that this study will help people to care more about their lifestyle and health.

\section{Compliance with ethical standards}

\section{Acknowledgments}

We would like to thank our supervisor, for her support and guidance through each stage of the process.

Also we would like to thank Philadelphia university-Biotechnology department and all doctors who supported us to reach this stage. 


\section{Disclosure of conflict of interest}

All authors confirmed that they have no conflict of interest.

\section{Statement of informed consent}

In the Google document survey form we make sure that all participants understand that their participation and results of this form will be used for included in this survey study.

We believe that the consent is informed well and that all individual participants included in the study understands the implications of participation.

\section{References}

[1] Weiss SR, Navas-Martin S. Coronavirus Pathogenesis and the Emerging Pathogen Severe Acute Respiratory Syndrome Coronavirus. ASFM microbiology and molecular biology review. 2005; 69: 635-664.

[2] Joyce Almeida. June Almeida (née Hart). NCBI PMC. 2008; 336: 1511.

[3] Tyrrell, Almeida, Cuuningham, Doedle, Hofasted, Tajima et al. Coronaviridae. Karger. 1975; 5: 76-82.

[4] Fung, DX Liu. Human Coronavirus: Host-Pathogen Interaction. Annual Review of Microbiology. 2019; 73: 529557.

[5] JSM Ppeiris, ST Lai, LLM Poon, Y Guan, LYC Yam, W Lim, et al. Coronavirus as a possible cause of severe acute respiratory syndrome. The lancet. 2003; 361: 1319-25.

[6] Ali M Zaki, Sander van Boheemen, Theo M Besrebroer, Albert Ron AM, et al. Isolation of a Novel Coronavirus from a Man with Pneumonia in Saudi Arabia. The New England Journal of Medicine. 2012; 367: 1814-1820.

[7] Q Li, Guan X, Wu P, Wang X, Zhou L, Tong Y, Ren R, Leung K, SM Lau, EHY et al. Early transmission dynamics in Wuhan, China, of novel coronavirus-infected pneumonia. The New England Journal of Medicine. 2020; 382: 11991207.

[8] Shibo Jiang, Zhengli Shi, Yuelong Shu, Jingdog Song, et al. A distinct name is needed for the new coronavirus. The Lancet. 2020; 395: 949.

[9] Wei ji, Wei Wang, Xiaofang Zhao, Junjie Zai, Zingguang Li, et al. Cross-species transmission of the newly identified coronavirus 2019-nCoV. Wiley journal of medical virology. 2020; 92: 433-440.

[10] Ivan Seah, Rupesh Agrawal. Can the coronavirus disease 2019 (COVID-19) affect the eyes? A review of coronaviruses and ocular implications in humans and animals. Ocular Immunology and Inflammation. 2020; 38: 391-395.

[11] cornelis AM, Lili kuo Paul S, Harry vennema, Peter JM. Coronavirus particle assembly: primary structure requirements of the membrane protein. American society for microbiology journals. 1998; 72(8): 6838-6850.

[12] Patric CY, Yi huang, Susanna KP, kwok -yung yuen. Coronavirus genomics and bioinformatics analysis. Viral genomics and bioinformatics. 2010; 2: 1804-1820.

[13] Sander van Boheemen, Miranda de Graaf, Chris Lauber, Theo M. Bestebroer, Ali Moh Zaki, Albert DME. Osterhaus, et al,. Genomic characterization of a newly discovered coronavirus associated with acute respiratory distress syndrome in humans. American society for microbiology. 2012; 3(6): e00473-12.

[14] Alexander E, Luis enjuanes, Eric J, John Ziebhur. Nidovirales: evolving the largest RNA virus genome. Science direct Virus research. 2006; 117: 17-37.

[15] Stanley Perlman, Jason Netland. Coronaviruses post-SARS:Update on replication and pathogenesis. Nature Reviews Microbiology. 2009; 7: 439-450.

[16] Emmie de Wit, Neeltje van Doremalen, Darryl Falzarano, Vincent J Munster. SARS and MERS: recent insights into emerging coronaviruses. Nature Reviews Microbiology. 2016; 14: 523-534.

[17] Lan J, Ge J, Yu J, et al. Structure of the SARS-CoV-2 spike receptor-binding domain bound to the ACE2 receptor. Nature. 2020; 581: 215-220.

[18] Anthony R, Stanley Perlman. Coronaviruses: An Overview of Their Replication and Pathogenesis. Springer link. 2015; 1282: 1-23. 
World Journal of Biology Pharmacy and Health Sciences, 2021, 05(02), 033-044

[19] Ahmad Alkhatib. Antiviral Functional Foods and Exercise Lifestyle Prevention of Coronavirus .MDPI Nutrients. 2020; $12: 26-33$.

[20] Minkyung Bae and Hyeyoung Kim. The Role of Vitamin C, Vitamin D, and Selenium in Immune System against COVID-19. MDPI Molecules. 2020; 25(22): 5346. 